\title{
A Making Conversation
}

\author{
Stacey Bush and Amanda Woodford \\ The MIECAT Institute, Australia
}

\begin{abstract}
In this paper we aim to demonstrate an approach to multi-modal arts making in a therapeutic arts practice. It is based on the teaching of 'Multi-modality', a Master's subject at The MIECAT Institute, in Melbourne, Australia. The focus of this subject is to describe interactions with materials and facilitate an emergent embodied engagement with tools, materials and arts making. By engaging in a similar process ourselves and presenting it here, our hope is to give an evocative sense of the kind of emergent inquiry we facilitate for our students- an emergent inquiry process of arts making that can create the basis of rich and meaningful inquiry into lived experience.
\end{abstract}

Keywords: multi-modality, emergent inquiry, arts making, therapeutic arts practice

\section{Hi Stacey,}

Let's begin as our recent 'Multi-modality' students did by 'walking in wonder': 'walking slowly, gently and intentionally, in order to notice the particular becomes an evocative space for visual living inquiry' (de Cosson, Irwin, Kind \& Springgay, 2007, p. 140).

From my 'slow walk' around the neighbourhood, I gather many photos and videos. To make these expressions manageable I cluster them into sets of four. I decide to select one of these which contains the three images below, for further exploration. My intention is to enter into a making conversation with my hands and materials, with an improvisational approach (Tufnell \& Crickmay, 2004).
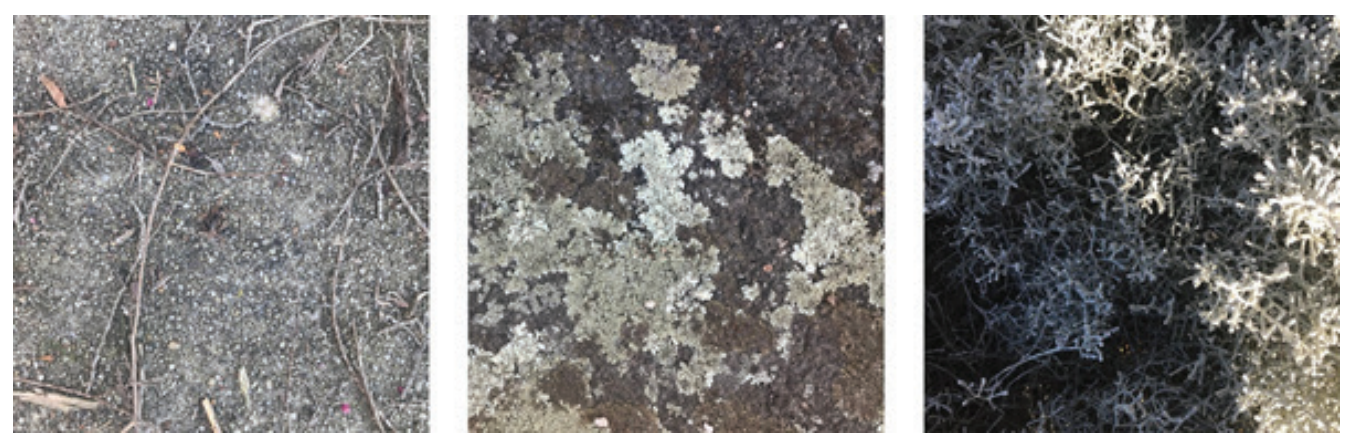

FIGURE 1 | Amanda, 2018, Cluster (digital photos) 
Amanda with anticipation I meet your text and images. A response bubbles forth...

Sinuous curves growing in a travelling upon ground

Growing in ground

Straight enough sticks creating patterned form upon ground

Patterns of spaces between places of intersection

A slow walk. That is my intention as I set out. At first I attend to slowing down. My pace, my breathing, slow looking all around, open sensing. Attending to what calls to me. In a quiet corner of my awareness your images travel with me. I am drawn to grass growing from a cavity. The darkness inside and worn curved edge feel alive.

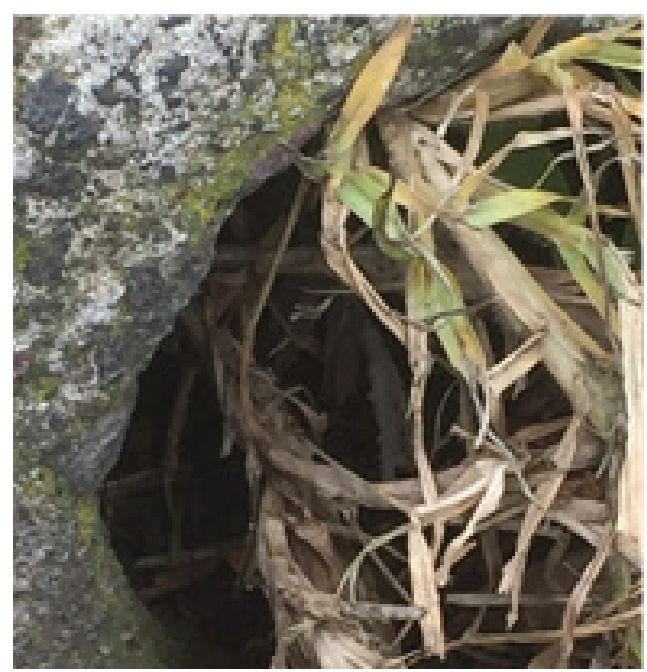

FIGURE 2 | Stacey, 2018, Grass growing from a cavity (digital photograph)

The human made meets the natural world. I begin to notice curves and patterns. There are many patterns. I walk, look, make rubbings, and take photographs.

Intersections

Curves

Human made

Imperfect 
Beautiful in their meeting the world, in their detail, in their decay. I begin to notice things that encroach, scattered fragments of earth, stone, concrete, plastic, possum droppings, fallen foliage, and plant growth all attesting to the embeddedness of the human made in our landscape.

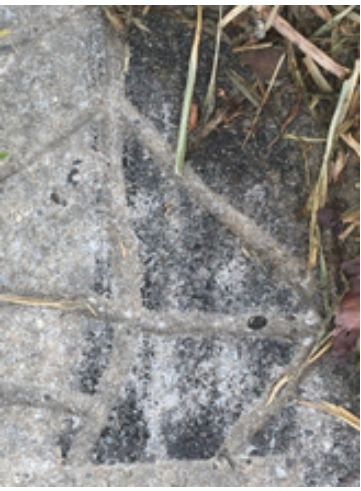

(a)

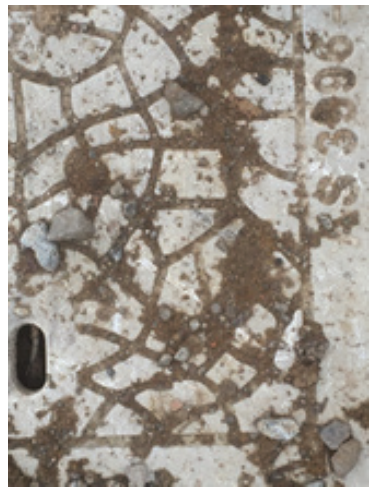

(b)

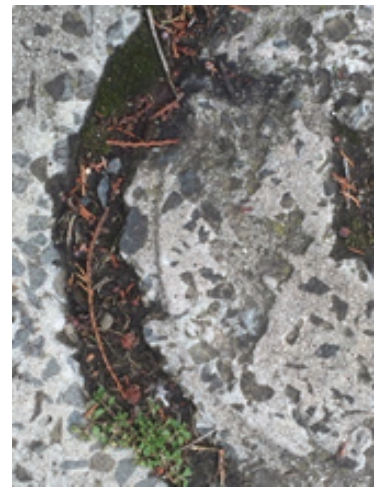

(c)

FIGURE 3 | (a) Stacey, 2018, Lines (digital photograph); (b) Stacey, 2018, Scattered fragments (digital photograph); (c) Stacey, 2018, Curves (digital photograph)

I walk contemplating ideas of layered embeddedness. Toward the end of my walk I encounter with a strange surprise and feeling of warm pleasure, three objects lying lightly upon - upon concrete, upon grass, not at all embedded. They are each very beautiful to me and leave me feeling uplifted.

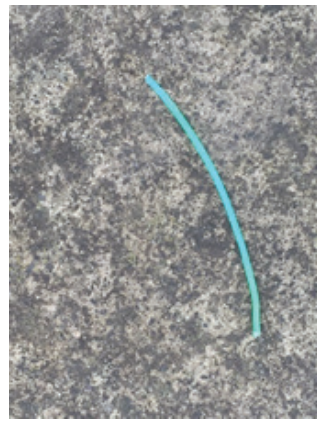

(a)

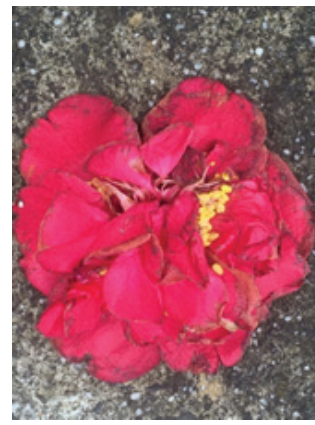

(b)

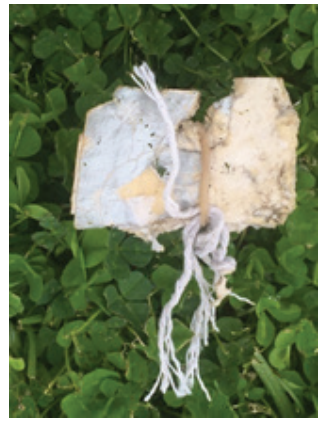

(c)

FIGURE 4 | (a) Stacey, 2018, Wire (digital photograph); (b) Stacey, 2018, Flower (digital photograph); (c) Stacey, 2018, Fraying (digital photograph)

Patterned repetition, embeddedness, and resting upon. Amanda, these are the things I am left reflecting on. 
Stacey, your words and images I find evocatively tactile. I sit down in the studio to begin arts making guided by what we have gathered. A piece of polystyrene block has been taunting me for the last few days. It is small with a circular embossed surface. I sense that if I print from it I might achieve the dappledness that I see in my images. But I really dislike the material for its environmental harm. I am disturbed by it.

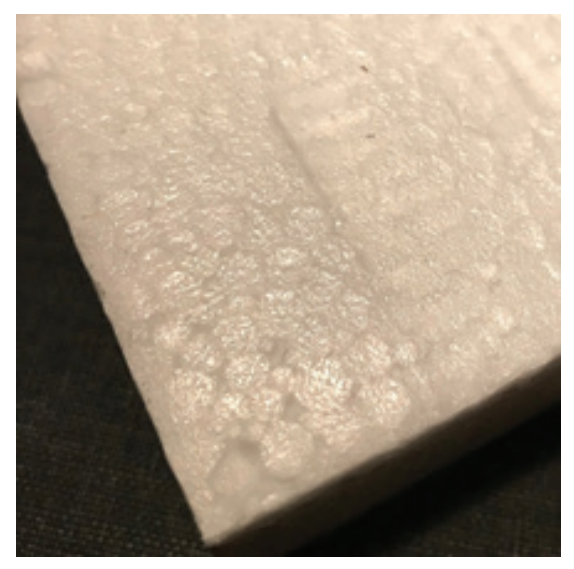

FIGURE 5 | Polystyrene block

However, from your words 'human made and patterns', I gain some form of permission to start with this disliked material - perhaps it is appropriate in its inappropriateness. I begin. I bracket-in black grey hues from the photos. The block resists my pigment, but surprisingly prints ok. The polystyrene feels awful to touch.

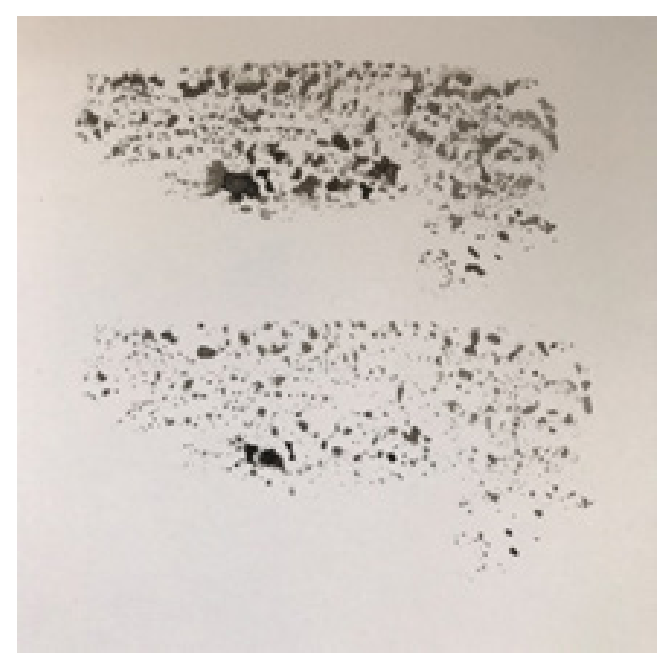

FIGURE 6 | Print \# 1 
I bracket-in 'patterns of spaces between places of intersection', amplifying the stamping, moving faster, repeating, searching.

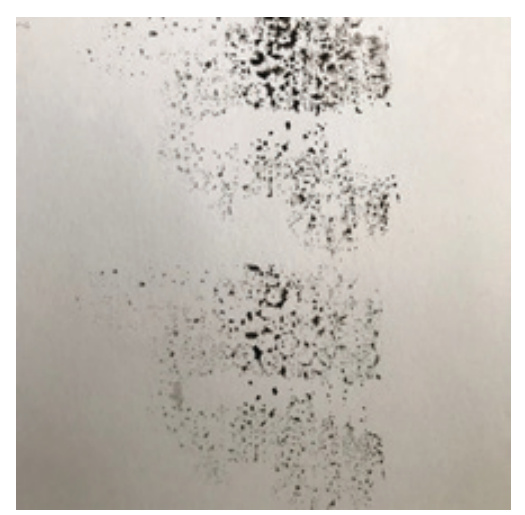

FIGURE 7 | Print \#2

To amplify further, I cover the whole block in ink, adding the greens and browns, more obvious in your photos than in mine. I hear the polystyrene scratch and creek under pressure, under my fingers.

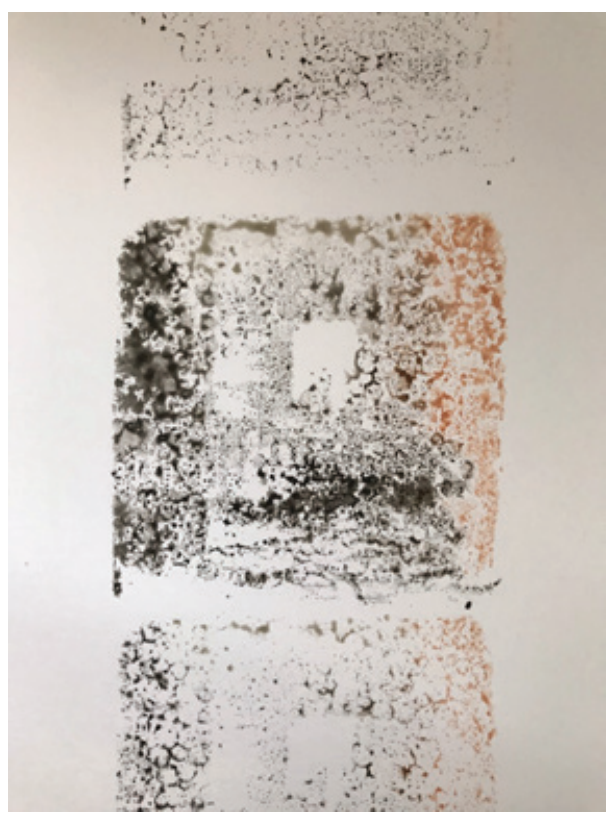

FIGURE 8 | Print \#3

I pause. Where is this inquiry going? I look to your images and words for navigation. 'Travelling', I do not see in my prints. However, I do see 'intersections, curves, human 
made and the imperfect'. I notice that 'decay' is missing. A chord strikes, plastics lack decay! My fingers tingle in disgust. To feel at ease, I need nature. The coloured flower in your image calls me forth. I go outside and collect a handful of similar petals, in varying states of decay.

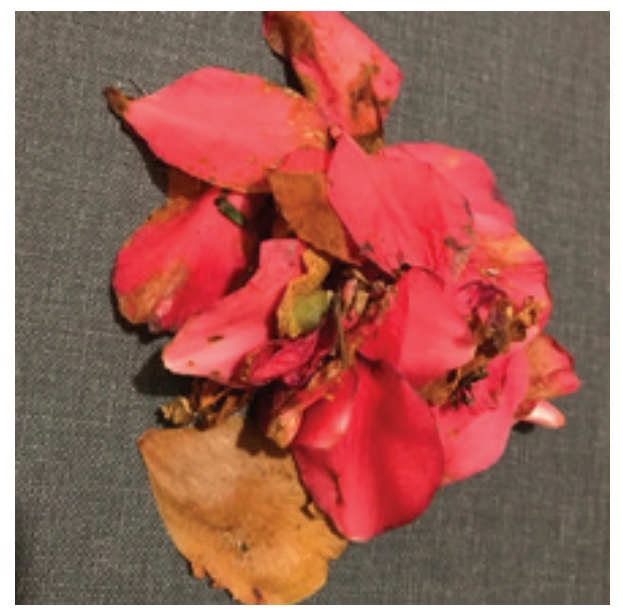

FIGURE 9 | Decaying petals

The petals are a little dirty, a little unpleasant to hold. I line them up based on their decay progression. Those that don't meet the line-up are returned outside.

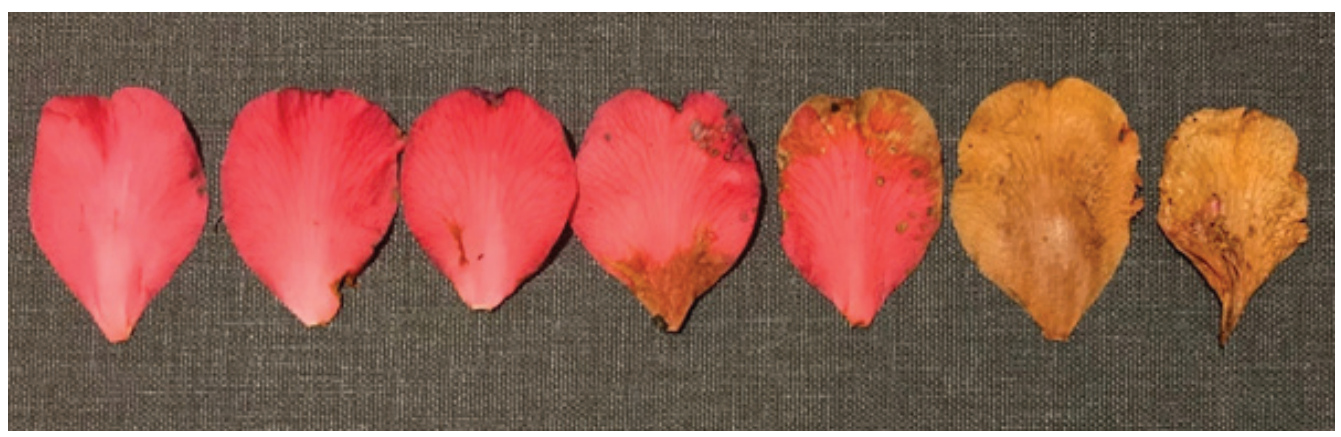

FIGURE 10 | Decay progression

I want to use the petals to mark a surface - to gain 'embeddedness'. Fabric seems a receptive surface. I squish the first petal into a panel of silk. The petal squeaks in response, as if I have caused harm. Discomfort ripples through my body. 


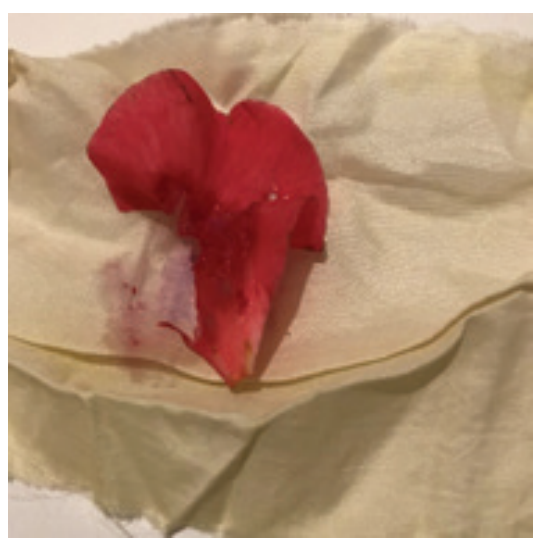

FIGURE 11 | Squished petal on fabric

I roll the petal in my fingers, a gentle movement. There is no pattern - instead organic movements unfold, my hands in movement, in connection to nature and the surface below.

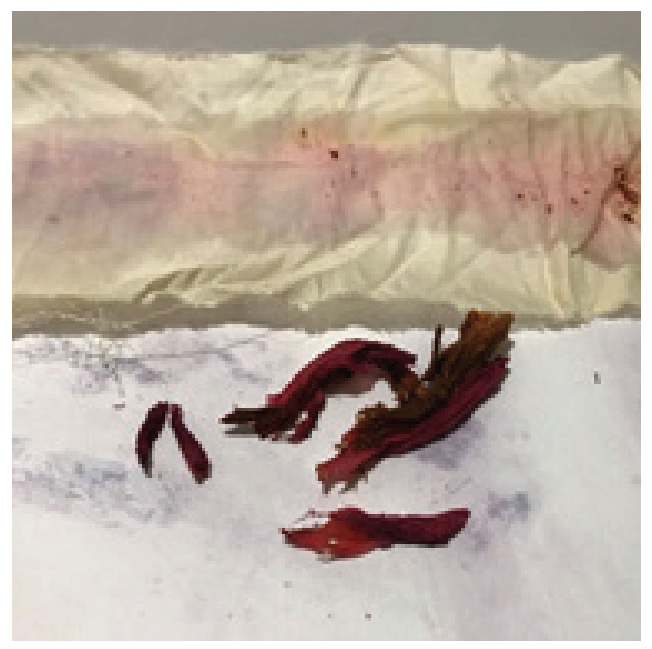

FIGURE 12 | Petals rolled on fabric

My fingers are sticky, I can smell the dampened, bruised petals. I bracket-in 'sinuous curves growing in a travelling upon ground'. I take a watersoluble pencil and travel, lines traverse horizontally and vertically down creases in the fabric, 'identifying places of intersection', appear. 


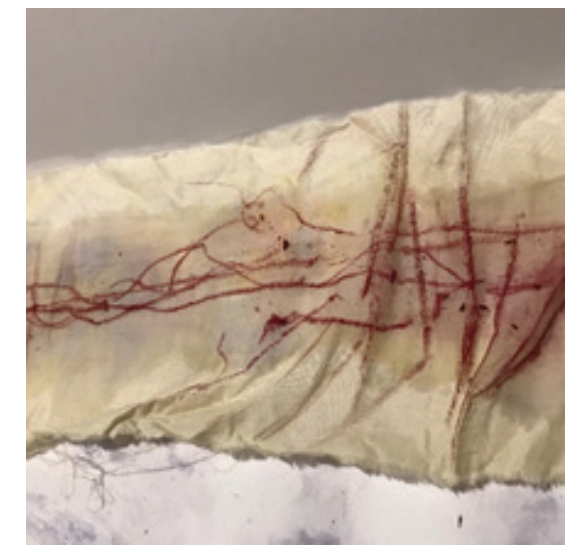

FIGURE 13 | Pencil lines travel on fabric

I hear the murmur of the dishwasher behind me, look up to lights illuminating above. My human made consumption conflicts with a value to care for the natural world. My heart sinks. I look back at our photos. I bracket in the fractured lines I see in your second cluster of images. With my scissors, I reduce the fabric to angled pieces. The fabric puckers under my blade. There are shadows and overlaps. I put the work aside.

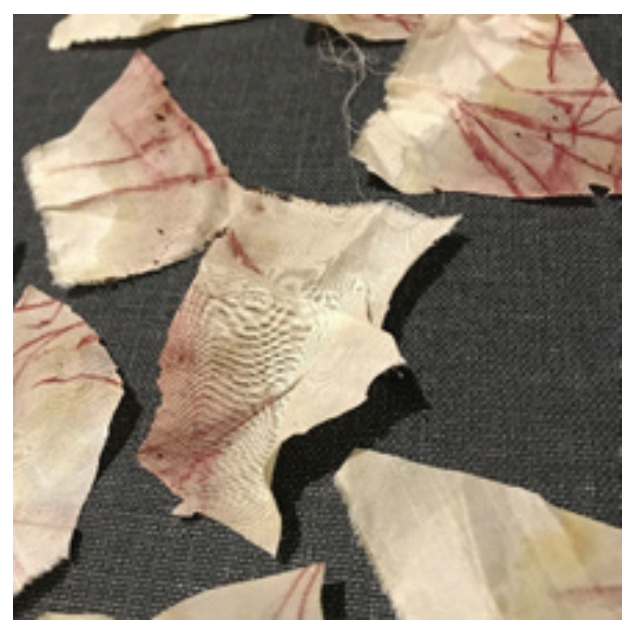

FIGURE 14 | Amanda, 2018, Fragments (silk fabric, petal stain and watersoluble pencil)

As I tidy, I pick up the bundles of petals, they squish in my fingers. With a light touch, I dab them onto a new page, bracketing-in 'pattern' but with an organic action. Their dampened smell returns to my nostrils. I notice that the lighter my touch the darker the impression. Then I widen my movements, hand sweeping, fingers gently rub colour to create a solid layer, 'a layer of embeddedness'. I tear the sheet to divide the patterned and the solid. 

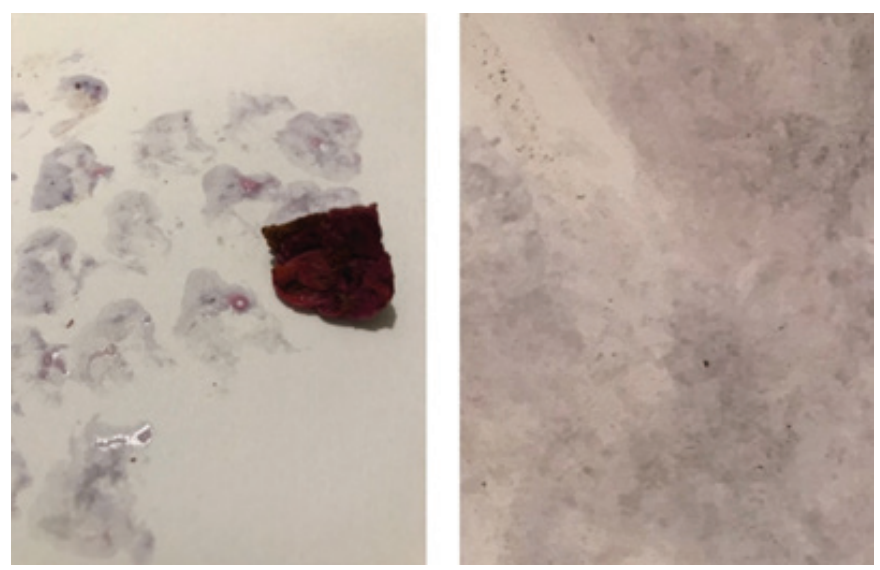

FIGURE 15 | Organic pattern (left) and solid 'layer of embeddedness' (right)

Through photography, something important resonates, yet I struggle to name exactly what 'it' is. I form together my loose knowings in poetic form, to accompany my photo.

$\underline{\text { Torn }}$

Marked by nature.

Fingers press,

getting sticky

a ball of decaying nature,

splotch, splotch, patterning,

the lighter the touch the greater the mark.

Sweeping, gentle rubbing,

no longer a pattern

becoming embedded,

colours the surface.

Then a divide appears,

uneven, a gulf with shadow and pointy edges.

Human made meets the natural world.

Stacey, as this work sits in front of me and my reliance on modern day comforts continue to whirl around, I consider the impact of the 'human made' as it 'meets the natural world'. I am curious to hear your response and perhaps how 'not at all embedded' might fit? The 'resting upon, lying lightly upon', left you feeling uplifted, this I wonder might be the missing element, to help me make sense of my work. 


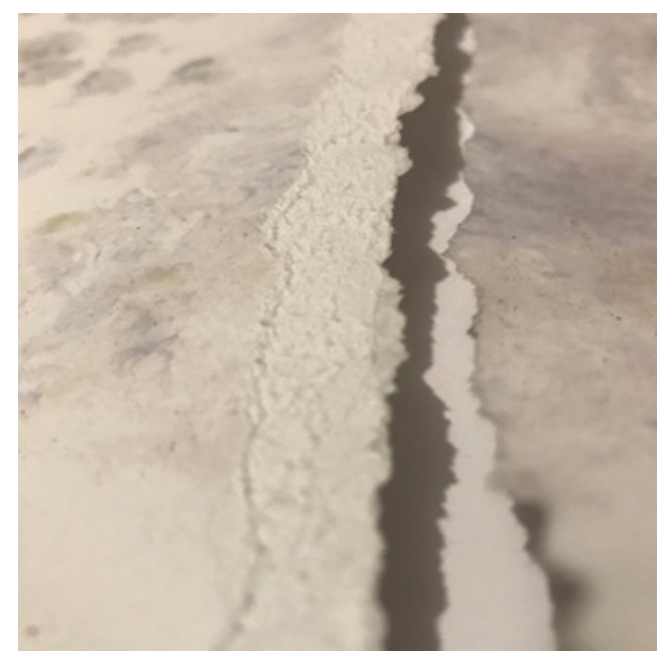

FIGURE 16 | Amanda, 2018, Torn (digital photograph)

Amanda, I receive your images and process of engaging with materials with great curiosity. Your last image of torn paper and light imprints of the bruised petals sparks something for me.

I recently rescued three wild kittens who had lost their mother. These three wild kittens lived in a room in my house for several weeks - a meeting of the wild and the human made. They very robustly, and noisily, engaged with their new environment. Balls of wool, paper bags, and pieces of rope were favourite play things. They became a little less wild as they became increasingly comfortable with my presence, familiar with feeding routines, and as they learnt to use litter trays. They became ready to move to an animal shelter after four to five weeks of living in my spare room. The house felt very quiet after they left, in the day or two following their departure it felt like their presence was indeed lying lightly upon the space, on my heart. Their absence was quite tangible.

I tell this story as what stays with me from your latest offering is the idea of printing and imprinting, your image of 'torn edges', and the invitation to consider 'resting lightly upon'. As I set about cleaning and clearing the room after the kittens left, I reflected on the imprints left by this wild nature meeting human made. I gathered what was left of the wool that is no longer in a ball, torn paper, and pieces of cardboard - their play things. I find a kickboard much altered as well. These are some perceptible imprints left by the kittens. 


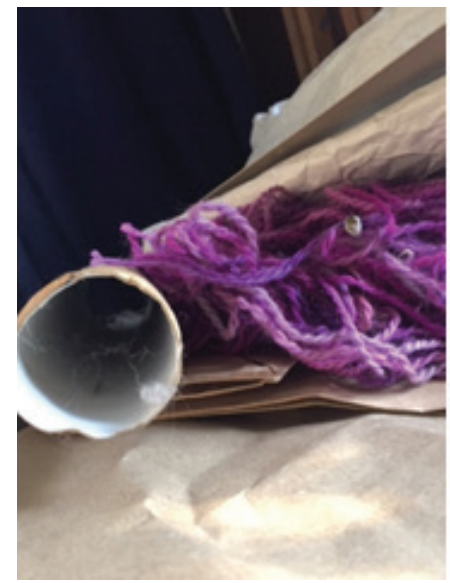

(a)

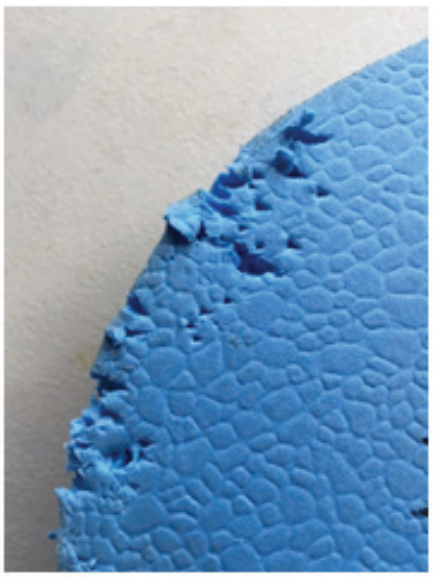

(b)

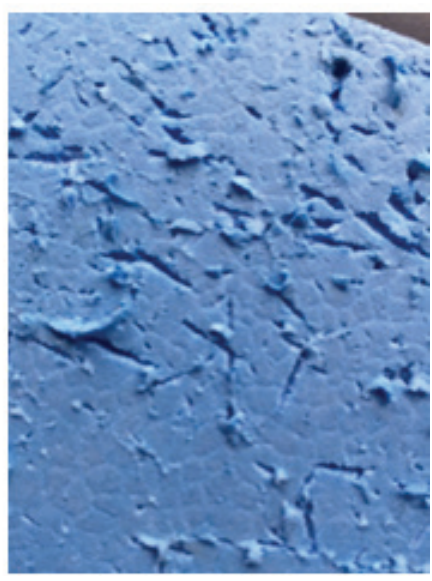

(c)

FIGURE 17 | (a) Stacey, 2018, Remains (digital photograph); (b) Stacey, 2018, Imprints 1 (digital photograph); (c) Stacey, 2018, Imprints 2 (digital photograph).

I notice that the scratch marks on the kick board are similar to your pencil marks on the silk Amanda.

In considering how to creatively respond to and engage with what might be 'not at all embedded', what might be 'resting lightly upon', I am at first quite unsure how to begin. It takes some time to feel into just what materials I want to engage with. What I am holding is a strong resonance with your images of the petal stained, pencil marked, and cut up silk pieces. Your marks speak to the kittens'scratch marks. There is something in the quality of the lines, a hatch working that resonates. Also alive for me are the torn edges of paper in your final image, this elicits a sense of separation, of space between, and also unpredictability. The feeling of this is similar to the feeling of absence I experienced after the kittens departed, their imprint left on me.

I am drawn to some heavy watercolor paper and find myself searching for something with a sharp point. I begin to scratch the surface of the paper, drawing in lines which leave little visible trace. As I am doing I am somehow also being led. I create two scratch drawings. The lines are embedded and yet my experience of them is that they rest lightly. This experience creates a feeling of intangibility and unpredictability. I know I am marking the paper and yet I cannot see the form of my markings, I have no idea what they might look like. It is quite difficult to photograph these scratch marks. I need to get up very close and approach at an angle. Even then the marks are illusive. I kind of like this, and while I am curious and at the same time uncertain, I trust this process will lead me somewhere. 


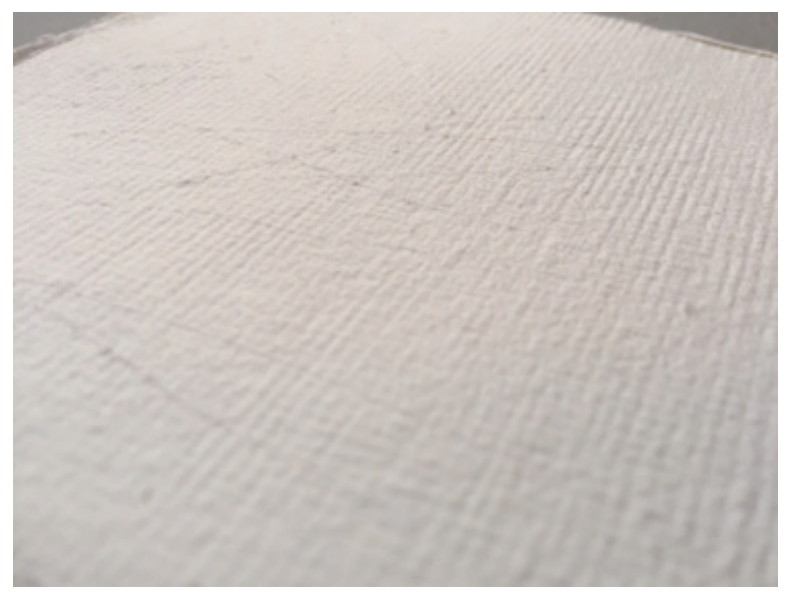

FIGURE 18 | (a) Stacey, 2018, Scratches (scratched paper, $8 \mathrm{~cm} \times 11 \mathrm{~cm}$ )

Wanting to see these marks more clearly I brush a light ink wash over the paper. The ink brings the lines to life, they emerge slowly as the ink soaks into the paper.

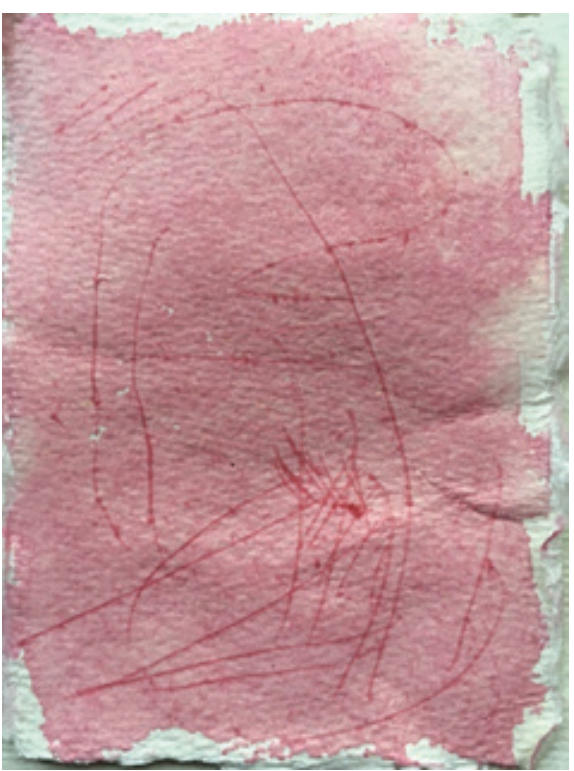

(a)

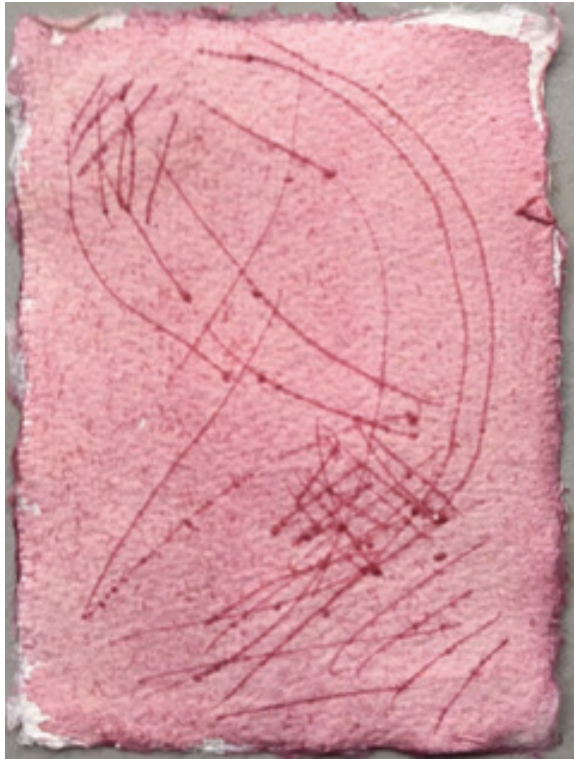

(b)

FIGURE 19 | (a) Stacey, 2018, Marks 1 (ink on paper, $8 \mathrm{~cm} \times 11 \mathrm{~cm}$ ); (b) Stacey, 2018, Marks 2 (ink on paper, $8 \mathrm{~cm} \times 11 \mathrm{~cm}$ ) 
I am happily surprised that the lines still hold a quality of lightness. The barely perceptible imprint has become tangible and visible.

I have a break and make my morning coffee. When I come back to the images I am shocked and quite disappointed to find that unexpectedly the lines all but disappear from view as the ink dries. Alongside the moment of shock is wonder at how an inquiry can lead us to unthought places when space is made for outcomes to be let go. I choose to stay with these now all but empty images.

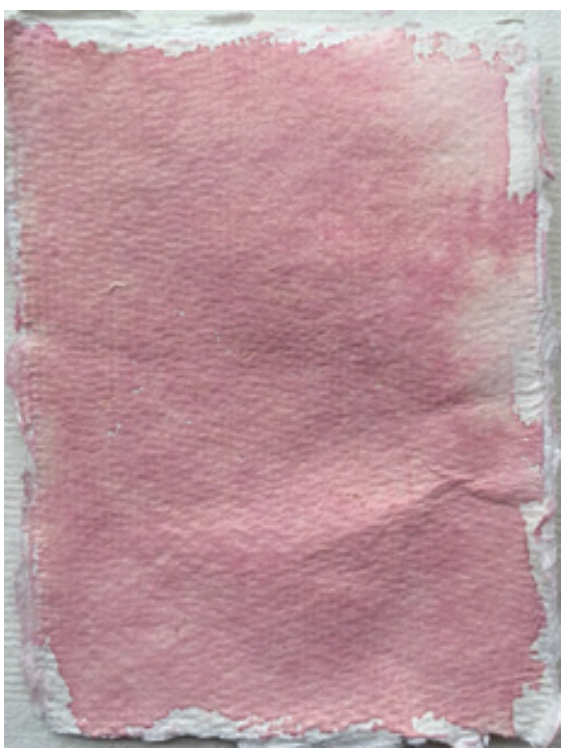

(a)

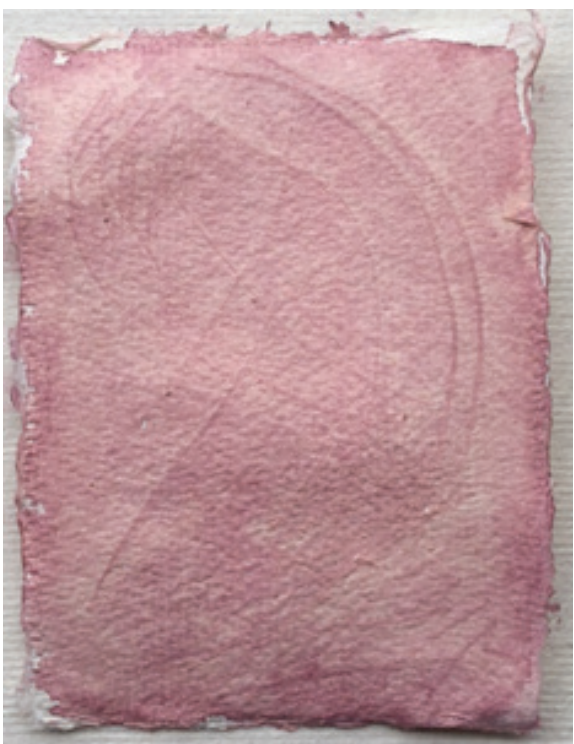

(b)

FIGURE 20 | (a) Stacey, 2018, Disappeared 1 (ink on paper, $8 \mathrm{~cm} \times 11 \mathrm{~cm}$ ); (b) Stacey, 2018, Disappeared 2 (ink on paper, $8 \mathrm{~cm} \times 11 \mathrm{~cm})$

This disappearance of image evokes a sense of loss, of absence, the same feeling as when the kittens left. I reflect on the space between absence and presence and am left with a palpable sense of having played in this space. I wonder at the sometimes intangible, and ineffable lightness of imprints made, the word fleeting comes to mind.

Scratched

Lines embedded

Yet in process

Rest lightly

Intangible imprints

In a place between

Absence and presence 
Intangible imprints

Made visible

For a while

Amanda this is what my process has brought up for me and I offer it to you in the hope it somehow meets your experiencing in a meaningful way. Alongside the indestructible and all too tangible embeddedness of yourpolystyrene, co-exists a fleeting and at times almost imperceptible subtlety of imprints left by things that 'rest lightly upon'. Traces left within absence that may be felt but not always seen or seen clearly. I wonder at the fullness of absence.

Hello Stacey,

I love the kittens! Their story and your offering nudged my inquiry along in a surprising, yet welcoming way. As our students have done, I continue to attend to my arts making whilst responding to materials, to land upon what I have come to know in an emergent artistic form. Stacey, I invite you to witness my landing place of inquiry (for now), in form and accompanying artist statement. The content that has emerged is for me significant and has opened up space for further reflection and reflexive action - the inquiry always continues. I thank you for travelling alongside in creative dialogue.

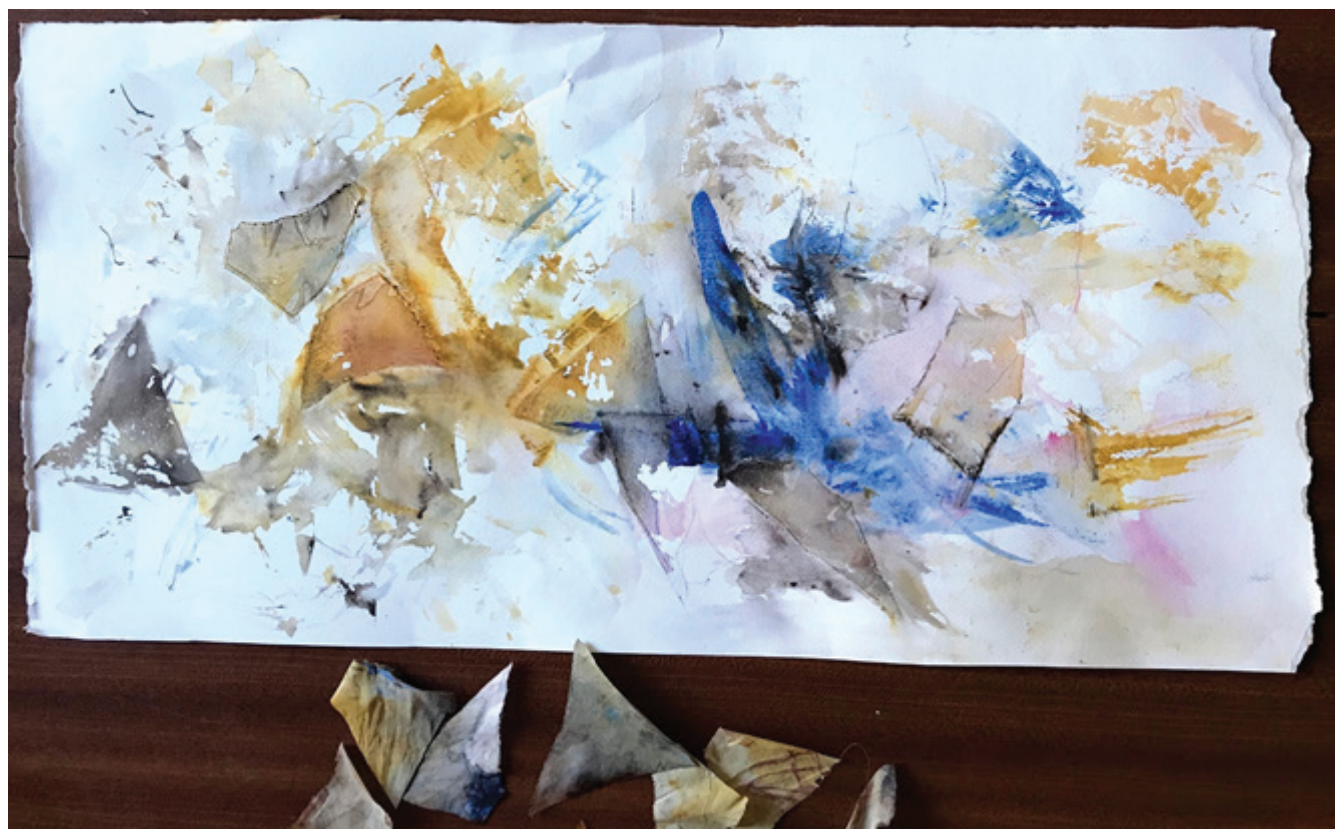

FIGURE 21 | Amanda, 2018, Traces (mixed media on paper, $70 \mathrm{~cm} \times 35 \mathrm{~cm}$ ) 


\section{Traces}

'Rest lightly, imprints, traces and absence', these words call me to begin. Materials with soft qualities, a bundle of fractured pieces and torn edges reply. Pressure, tools, water, and pigment surround the fractured, soaking through, leaving 'imprints, traces'. Shifting and moving in dialogue with each other, slowly momentum gathers, fingers gently press, leaving heavier marks than expected. Call in three wild kittens from a story told, fractured silk pieces leap across the page. Body moves, fingers stick, I am in it and so are they, all in play. Edges traced to track where once they sat, changed through interaction. 'Places of intersection', 'human' and other, perfectly 'imperfect'. Marks 'embedded', soaked, fingertips black. Scratched 'traces'. Removed pieces reveal spaces of absence, excitedly details remain. I step back and see a dynamic movement, our unique interaction. We are all participants living in this earth, human and non-human, with flows, rhythms, and tensions (Abram, 2010). Intertwined in a myriad of relationships. We leave 'traces', imprints from our moments in time.
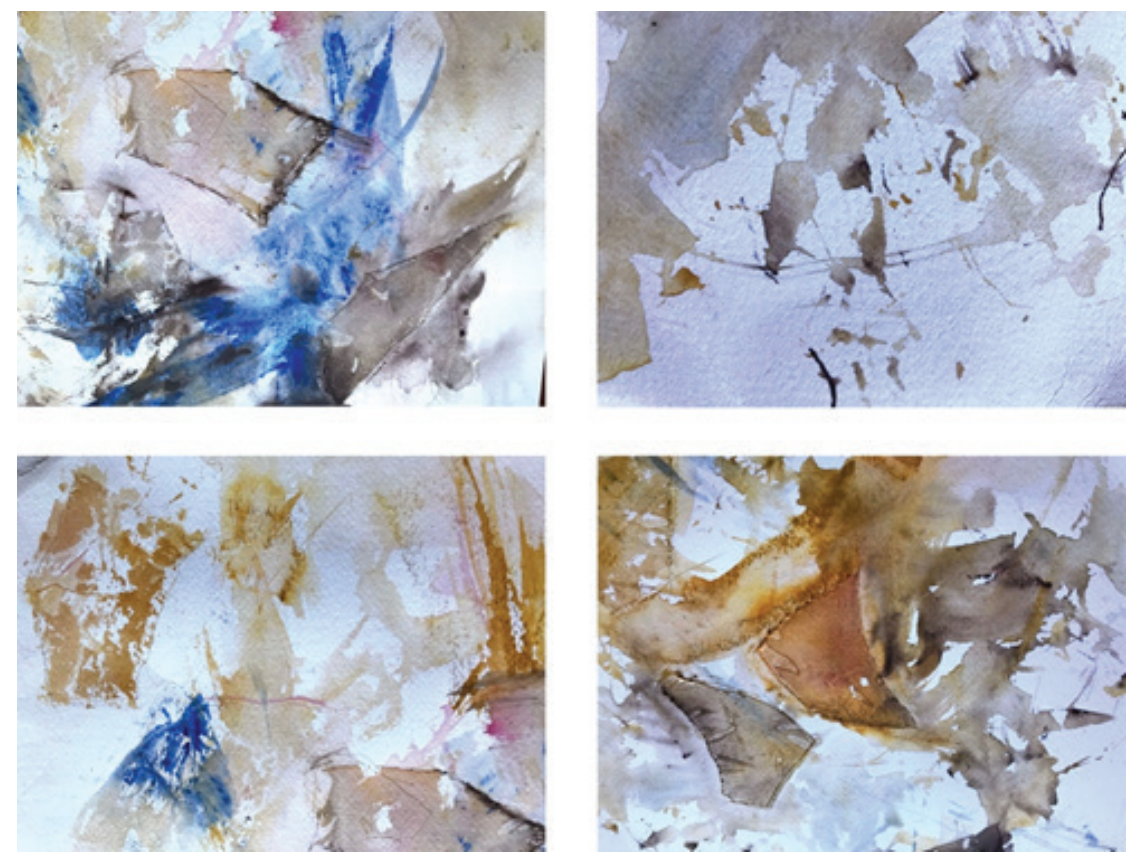

FIGURE 22 | Traces (close-up images)

Thank you Amanda for taking me on a walk along these pathways with you. I am left reflecting on how attentive engagement with the process of arts making can allow for a letting go and opening up to what is whatever unfolds. This brings to mind Levine's (2015) idea of 'poesis', where imaginative engagement 'requires a letting-go of 'end-gaming' and a willingness to explore whatever may come. It requires a giving-up of control 
and a willingness to "let something be"” (p. 17). With this attitude we attend to what presents and stay with that, we attend to moments of surprise and the unexpected and stay with them. For Gunaratnam (2007) 'staying with' can "enable a responsiveness... whilst receiving uncertainty and ambivalence" (p. 281). This way of being open to responding to these moments, letting go of outcome, and moving in the not quite known makes for an emergent inquiry process. "Our inquiry is always incomplete, always in becoming, emerging. As we seek clarification and elucidation of what we know, we are also constantly moving forward into new, as yet unknown, and sometimes unanticipated territories" (Bush, 2014, p.359). Amanda, we have worked emergently and followed our resonance to materials and arts making, co-creating new pathways as we explore - what a beautiful way to work.

\section{About the Authors}

Stacey Bush, ProfDoc, AThR, MA Creative Arts Therapy, GradDip Creative Arts Therapy, BA(hons) China Studies. Senior academic at The MIECAT Institute, Melbourne, Australia.

Amanda Woodford, AThR, MA Experiential Creative Arts Therapy (ECAT), GradDip ECAT. Arts therapist, artist, educator at The MIECAT Institute and Professional Doctorate candidate.

\section{Conflicts of Interest}

The authors declare no conflict of interest.

\section{References}

Abram, D. (2010). Becoming animal. An earthly cosmology. New York: Vintage Books.

Bush, S. (2014). Being with/in the space of us: An emergent arts inquiry (Doctoral dissertation). Retrieved from https://miecat.edu.au/research/

de Cosson, A. F., Irwin, R. L., Kind, S. \& Springgay, S. (2007). Walking in wonder: encountering the visual through living inquiry. In J. G. Knowles, T. C. Luciani, A. L. Cole \& L. Neilsen (Eds.), The art of visual inquiry (pp. 135-152). Nova Scotia, Canada: Backalong Books.

Gunaratnam, Y. (2007). Where is the love? Art, aesthetics and research. Journal of Social Work Practice, 21(3), 271-287. doi.org/10.1080/02650530701553518

Levine, S. K. (2015). The Tao of poesis: Expressive arts therapy and Taoist philosophy. Creative Arts in Education and Therapy: Eastern and Western Perspectives, 1(1), 15-25. doi: 10.15534/CAET/2015/1/4

Tufnell, M. \& Crickmay, C. (2004). A widening field: Journeys in body and imagination. Binsted, Hampshire: Dance Books. 